\title{
HUBUNGAN KANDUNGAN NITRAT DENGAN DENSITAS ZOOXANTHELLAE PADA BEBERAPA JENIS KARANG DI REEF FLAT PULAU PARI KEPULAUAN SERIBU JAKARTA
}

\author{
The Relation between Nitrate with Zooxanthellae Density in some type of Coral \\ Reef Flat in Pari Island Thousand Islands Jakarta
}

\section{Nur Latifah Khuzma, Agung Suryanto*), Pujiono Wahyu Purnomo}

\author{
Program Studi Manajemen Sumberdaya Perairan \\ Fakultas Perikanan dan Ilmu Kelautan, Universitas Diponegoro \\ J1. Prof. Soedarto, SH, Tembalang, Semarang, Jawa Tengah - 50275, Telp/Fax. +62247474698 \\ Email: Nurlatifahkhuzma@yahoo.com
}

\begin{abstract}
ABSTRAK
Pulau Pari merupakan salah satu pulau yang berada di tengah-tengah gugusan. Terumbu karang merupakan ekosistem pesisir yang memiliki produktivitas tinggi. Nitrat merupakan nutrien sebagai salah satu faktor penentu terpeliharanya produktivitas perairan, maka penelitian ini akan mempelajari dukungan nitrat di dalam polip karang dan pengaruhnya terhadap keberadaan zooxanthellae. Tujuan dari penelitian ini adalah untuk mengetahui keberagaman jenis karang, faktor lingkungan yang mempengaruhi karang, kandungan nitrat dan densitas zooxanthellae pada beberapa jenis karang di reef flat Pulau Pari Kepulauan Seribu Jakarta. Penelitian ini dilaksanakan pada bulan Maret-April 2016 dengan metode deskriptif. Hasil penelitian yang diperoleh jenis karang yang dominan adalah Acropora sp., Porites sp., dan Montipora sp., dengan penutupan karang hidup di stasiun I (dermaga) 36,4\% kategori sedang, stasiun II (pemukiman penduduk) 22,4\% kategori buruk dan stasiun III (jauh dari aktivitas penduduk) $67,2 \%$ kategori baik. Koefisien determinasi $\mathrm{R}^{2}$ antara nitrat dengan densitas zooxanthellae pada masing-masing jenis karang dominan memiliki nilai $\mathrm{R}^{2}$ yang berbeda yaitu karang Acropora palifera diperoleh $\mathrm{R}^{2}=0.787$ dapat diartikan bahwa variabel bebas $\mathrm{X}$ memiliki pengaruh kontribusi sebesar $78,7 \%$ terhadap variabel Y 21,3\%, pada jenis karang Acropora divaricata diperoleh $\mathrm{R}^{2}=0.989$ memiliki pengaruh kontribusi sebesar 98,9\% terhadap variabel Y 1,1\% dan jenis karang Porites cylindrica $\mathrm{R}^{2}=0.955$ memiliki pengaruh kontribusi sebesar 95,5\% terhadap variabel Y 4,5\% lainnya dipegaruhi faktor lain diluar variabel X dari hasil tersebut menunjukkan bahwa nilai $\mathrm{R}^{2}$ diatas 0,5 yang berarti semakin erat hubungan antara variabel $\mathrm{X}$ dan $\mathrm{Y}$. Semakin tinggi kandungan nitrat di dalam polip karang, maka semakin tinggi pula densitas zooxanthellae yang dikandungnya.
\end{abstract}

Kata kunci: Beberapa Jenis Karang; Nitrat; Densitas Zooxanthellae; Pulau Pari

\section{ABSTRACT}

Pari Island is one island in the middle of the Thousand Islands cluster. Nitrate is a nutrient as a determining factor for the preservation of marine productivity, nutrients becomes an important factor. The problem is, whether the support is derived from the availability of nitrate in the water or in the coral polyps. Related to the above, this research will study the nitrate support in coral polyps and their effects on the presence of zooxanthellae. The purpose of this study is to determine the diversity of coral species, environmental factors affecting the coral, nitrate content and the density of zooxanthellae in some types of coral on the Pari Island Reef Flat in Thousand Islands Jakarta. This study was conducted in March to April 2016, with descriptive method. The results obtained are the the dominant coral species Acropora sp., Porites sp., and Montipora sp., With live coral cover in the station I (pier) of $36,4 \%$ medium category, station II (residential) of $22.4 \%$ poor category and station III (away from the population activity) of $67,2 \%$ good category.The coefficient of $R^{2}$ determination between nitrate with a density of zooxanthellae in each the dominant coral species have different values $R^{2}$ is Acropora palifera obtained $R^{2}=0.787$ means that the independent variable $X$ has the effect of a contribution of 78,7\% to $21,3 \% Y$ variables, the coral species Acropora divaricata obtained $R^{2}=0.989$ has the effect of a contribution for $98,9 \%$ to $1,1 \% Y$ variables and coral species Porites cylindrica $R^{2}=0.955$ has the effect of a contribution of 95,5\% to other variable $Y 4,5 \%$ influenced other than the variable $X$ of the results showed that the value of $R^{2}$ above 0,5 which means that the closer the relationship between the variables $X$ and $Y$. the higher the nitrate content in coral polyps, the higher the density of zooxanthellae contains.

Keywords: Types of Corals; Nitrate; Zooxanthellae Density; Pari Island

*) Penulis Penanggungjawab

${ }^{2 \odot}$ Copyright by Management of Aquatic Resources (MAQUARES) 


\section{PENDAHULUAN}

Pulau Pari merupakan salah satu pulau yang berada di tengah-tengah gugusan Kepulauan Seribu. Letak

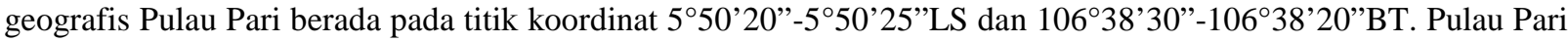
memiliki pantai yang berpasir putih dan perairan yang jernih, sehingga menjadi salah satu objek wisata di Kepulauan Seribu. Sebagaimana hal tersebut dengan gugusan pulau-pulau di Kepulauan Seribu, Jakarta di kawasan perairan Pulau Pari juga mempunyai terumbu karang yang membentuk sebuah ekosistem yang khas daerah tropis (ekosistem terumbu karang) (Candrasari et al., 2012).

Ekosistem terumbu karang merupakan bagian dari ekosistem laut karena menjadi sumber kehidupan bagi beraneka ragam biota laut di perairan (Dahuri, 1999). Ekosistem ini terdapat di laut dangkal yang hangat dan bersih, dan merupakan perairan paling produktif di perairan laut tropis, serta memiliki keanekaragaman hayati yang sangat tinggi. Terumbu karang merupakan ekosistem perairan yang susunan utamanya adalah hewan karang (polip) penyusun terumbu bersimbiosis dengan sejenis tumbuhan alga yang disebut zooxanthellae. Zooxanthellae berada di dalam polip karang sebagai pemasok nutrien bagi karang karena dapat berfotosintesis dengan bantuan sinar matahari yang menghasilkan energi dan oksigen untuk polip karang.

Terumbu karang di Pulau Pari mempunyai tipe terumbu karang pantai (Fringing reef) yang dicirikan dengan tumbuhnya karang di sekitar pulau. Reef flat merupakan salah satu habitat dari terumbu karang yang keberadaanya relatif rata dengan kedalaman di bawah 3 meter.

Secara struktural daerah reefflat hidup beberapa jenis karang yang mempunyai peran sebagai penyeimbang pulau karena keberadaan terumbu karang dapat menghalangi gelombang tinggi yang datang ke arah pesisir pantai. Dalam menopang peran fungsional dalam polip karang terdapat zooxanthellae yang menyuplai $98 \%$ kehidupan terumbu karang. Kehidupan dari zooxanthellae juga sangat dipengaruhi oleh nitrat $\left(\mathrm{NO}_{3}\right)$ sebagai penunjang laju pertumbuhan zooxanthellae dalam tubuh karang. Menurut Marubini (1996), nitrat yang tinggi di perairan dapat meningkatkan densitas zooxantellae, hal ini dapat menyebabkan perubahan keseimbangan terhadap energi, karbonioksida dan transport nutrient dari zooxantellae ke karang.

Dalam rangka keberlangsungan ekosistem terumbu karang khususnya pada kawasan reef flat, diperlukan informasi kepastian mengenai densitas zooxanthellae dan kandungan nutrien pada polip karang. Terkait dengan hal tersebut, maka penelitian ini akan mempelajari dukungan nutrien di dalam polip karang dan pengaruhnya terhadap keberadaan zooxanthellae.

\section{MATERI DAN METODE PENELITIAN}

\section{A. MATERI PENELITIAN}

Materi yang digunakan dalam penelitian ini adalah nitrat dan zooxanthellae dalam polip beberapa jenis karang dan parameter lingkungan fisika dan kimia. Alat yang digunakan untuk sampling lapangan adalah GPS (Global Positioning System), roll meter, secchi disc, water quality checker, bola arus, termometer, cool box, mortal dan alu. Alat yang digunakan untuk uji laboratorium adalah mikroskop opticlab, haemocytometer, centrifuge, timbangan elektrik dan spektrofotometer.

\section{B. METODE PENELITIAN}

Metode yang digunakan dalam penelitian ini adalah metode deskriptif, dengan tujuan untuk mengetahui gambaran suatu objek pengamatan dan dapat menjelaskan perkembangan yang terjadi pada kondisi pengamatan. Menurut Notoatmodjo (2002), penelitian bersifat deskriptif dengan tujuan utama memberi gambaran atau deskripsi tentang suatu keadaan secara objektif.

\section{Pengambilan sampel}

Metode pengambilan sampel menggunakan metode purposive sampling, yaitu pengambilan sampel secara sengaja, sesuai dengan persyaratan sampel yang diperlukan dengan asumsi bahwa sampel yang diambil dapat mewakili populasi dari lokasi penelitian.

Pada penelitian ini penerapan metodelogi terutama diarahkan pada pemilihan lokasi sampling yang terdapat beberapa jenis karang dominan pada kawasan reef flat.Pengukuran kualitas perairan pada lokasi sampling juga dibutuhkan sebagai data pendukung seperti: suhu, kecerahan, kecepatan arus, $\mathrm{pH}$, salinitas dan oksigen terlarut. Pengukuran kualitas perairan dilakukan secara in situ di setiap titik pengamatan dengan pengulangan sebanyak tiga kali.

\section{Penentuan lokasi sampling}

Stasiun pengambilan sampel dibagi menjadi tiga pada kawasan fringing reef, yaitu stasiun I dengan kawasan fringing reef dekat dengan aktivitas penduduk (dermaga), stasiun IIkawasan fringing reef di daerah pemukiman warga dan stasiun III kawasan fringing reef yang jauh dengan pemukiman warga. 



Sumber :Google Earth 2016

Gambar 1. Peta Lokasi Penelitian

\section{Pelaksanaan sampling}

Lokasi sampling dipilih berdasarkan aktivitas yang mempengaruhi kualitas terumbu karang, kualitas perairan dan kandungan nutrien yang berbeda karena masukan dari aktivitas di sekitar lokasi yang dibuang ke perairan. Setiap stasiun diambil jenis karang yang paling dominan, masing-masing jenis karang diambil dua fragmen karang untuk pengukuran densitas zooxanthellae dan nitrat pada polip karang. Pengambilan air sampel tiap stasiun diambil sampel air untuk pengukuran nitrat pada perairan.

\section{Kualitas air}

Peneitian ini memiliki faktor utama kualitas air seperti pengukuran suhu dan salinitas yang sangat berpengaruh terhadap ekosistem terumbu karang. Faktor pendukung seperti kecepatan arus, kecerahan, kedalaman, $\mathrm{pH}$ dan oksigen terlarut.

\section{Kualitas terumbu karang}

Tujuan dilakukan pengukuran kondisi terumbu karang adalah untuk melihat gambaran luasan karang hidup serta jenis genus yang mendominasi di lokasi penelitian. Pengukuran dilakukan dengan menggunakan metode Line Intercept Transect (LIT). Menurut English et al., (1997)), persentase karang hidup, mati, pasir dan pecahan karang dihitung dengan menggunakan rumus :

$$
\mathrm{C}=\frac{L}{2} \times 100 \%
$$

Keterangan:

C : Persentase penutupan terumbu karang

$\mathrm{Li}$ : Total penutupan karang

$L \quad$ : Panjang intercept koloni karang yang dilewati garis transek

6. Tahap pengambilan zooxanthellae dari jaringan polip

Pengambilan sampel karang dilakukan dengan memotong fragmen karang sepanjang 2-4 cmmenggunakan tang dan dimasukkan ke dalam botol sampel atau plastik yang berisi air laut dari lokasi yang sama dan ditambahkan formalin $10 \%$ untuk pengawetan.

\section{Tahap penghitungan zooxanthellae}

Menurut Norderman et al. (2003), konsentrasi zooxanthellae dalam polip karang dipergunakan sebagai variabel utama kajian ini. Berkenaan dengan pengukuran peubah ini, maka dilakukan urutan pekerjaan sebagai berikut:

- Mengambil sebagian spesimen karang, kemudian dicacah pelan dengan menggunakan mortal dan alu hingga hancur dan zooxanthellae lepas;

- Tuangkan ke dalam cawan petridish dan dihomogenisasi dengan alat centriefuge selama 10 menit dengan kecepatan 2500-3000 rpm untuk memisahkan supernatanya;

- Supernatanya dianalisis dengan menggunakan haemocytometer; 
- Pengamatan densitas zooxanthellae dengan menggunakan haemocytometer, dengan mikropipet yang diambil dari supernatan dan diletakkan di haemocytometer kemudian amati secara langsung dengan menggunakan mikroskop optic lab dengan perbesaran 100x. Jumlah zooxhantellae dihitung didasarkan kepada luas daerah. berikut :

Menurut Manuputty (1999), densitas sel zooxanthellae diperoleh berdasarkan perhitungan rumus sebagai

$$
\mathrm{D}=\frac{\mathrm{Q} \times \mathrm{P} \times 10000}{\mathrm{~L}}
$$

Keterangan :

$\begin{array}{ll}\mathrm{D} & \text { : Densitas Zooxanthellae } \\ \mathrm{Q} & \text { : Jumlah Perhitungan } \\ \mathrm{P} & \text { : Pengenceran } \\ 10000 & \text { : Konversi } 0.1 \mathrm{~mm}^{3} \text { menjadi } 1 \mathrm{~cm}^{3} \\ \mathrm{~L} & \text { : Luas Fragmen Karang }\end{array}$

8.Analisa kimia terhadap kadar nitrat pada polip karang.

Menurut Hutagalung dan Rozak (1997), ekstraksi sampel untuk analisis nitrat dan fosfat dengan cara sebagai berikut:

- Preparasi Sampel dilakukan dengan cara mengeringkan sampel polip karang menggunakan oven, kemudian menghaluskan karang dengan cara ditumbuk;

- Menimbang 2 gram sampel dengan teliti dan dimasukkan kedalam botol, kemudian ditambahkan larutan pengekstrak Bray I sebanyak 14 ml, kocok selama 1 menit. Lalu menyaring dengan kertas saring Whatman, hasil saringan siap untuk dianalisis nitrat dengan menggunakan prosedur kualitas air.

\section{Analisa kimia terhadap kadar nitrat perairan}

Sampel air laut yang telah diambil pada stasiun I, II dan III diambil 1 botol sampel air sebanyak $200 \mathrm{ml}$ serta dimasukkan ke dalam botol sampel dan diberi label, sampel air untuk pengujian nitrat diawetkan dengan 5 tetes $\mathrm{H}_{2} \mathrm{SO}_{4}$ dan dimasukkan dalam cool box, kemudian dibawa ke laboratorium untuk dilakukan pengukuran menggunakanspektrofotometer.

Menurut (SNI 01-3554-2006), pengukuran nitrat dengan cara10 ml sampel air limbah dimasukkan ke dalam tabung reaksi dimana sebelumnya sudah disaring dengan menggunakan kertas saring agar sampel tidak keruh. Lalu, $10 \mathrm{ml}$ sampel air limbah tersebut ditambahkan dengan $1 \mathrm{ml} \mathrm{HCl} 1 \mathrm{~N}$. Selanjutnya dikocok dan dibiarkan selama 10 menit. Warna kuning yang terjadi diukur intensitasnya dengan spektrofotometer uv-visible (Thermoscientific genesys 10S) pada panjang gelombang $220 \mathrm{~nm}$ dan $275 \mathrm{~nm}$.

Pembuatan kurva kalibrasi dapat dilakukan dengan membuat larutan standar nitrat 0,$00 ; 1,0 ; 5,0 ; 10 ;$ dan 1,5 $\mathrm{mg} / \mathrm{l}$ dengan cara mengencerkan larutan standar nitrat $100 \mathrm{mg} / \mathrm{l}$. Selanjutnya melakukan prosedur yang sama seperti terhadap sampel air limbah pada $10 \mathrm{ml}$ tiap larutan standar. Perhitungan kadar nitrat (mg/l) dilakukan dengan mengurangi pembacaan absorben larutan standar nitrat dan sampel air limbah dari panjang gelombang 220 $\mathrm{nm}$ dengan panjang gelombang $275 \mathrm{~nm}$. Kemudian, membuat kurva kalibrasi antara absorban dari hasil pengurangan tersebut dengan konsentrasi $(\mathrm{mg} / \mathrm{l})$, dan menentukan persamaan garis linearnya. Perhitungan konsentrasi nitrat pada sampel air limbah dengan menggunakan rumus sebagai berikut ini:

$$
\mathrm{NU}_{3}-\mathrm{N}(\mathrm{mg} / \mathrm{l})=\frac{y-\mathrm{a}}{\mathrm{b}}
$$

Keterangan:

$$
\begin{array}{ll}
\mathrm{NO}_{3}-\mathrm{N} & : \text { Konsentrasi nitrat }(\mathrm{mg} / \mathrm{l}) \\
\mathrm{y} & : \text { Absorbansi sampel } \\
\mathrm{a} & : \text { Intersep pada persamaan linear } \\
\mathrm{b} & : \text { Slope pada persamaan linear }
\end{array}
$$

\section{Evaluasi Data}

Evaluasi data yang digunakan adalah uji analisa regresi linier sederhana pada Microscoft Excel 2007. Menurut Hartono (2008), uji regresi linier sederhana digunakan untuk memprediksi pengaruh variabel bebas (nilai total nitrat) terhadap variabel terikat (densitas zooxanthellae pada polip karang). Untuk menunjang penggunaan uji tersebut dilakukan uji normalitas dengan Uji Liliefors pada Microscoft Excel 2007. Menurut Kadir (2015), uji normalitas galat taksiran digunakan sebagai persyaratan dalam analisis regresi untuk melihat distribusi sampel yang terpilih berasal dari distribusi populasi normal atau tidak normal.

\section{HASIL PEMBAHASAN}

\section{Keadaan Umum Lokasi Penelitian}

Pulau Pari merupakan salah satu pulau yang berada di Kecamatan Kepulauan Seribu Selatan, Kabupaten Kepulauan Seribu, Jakarta Utara. Pulau Pari terletak di tengah gugusan pulau yang berderet dari Selatan ke Utara Jakarta. Letak geografis Pulau Pari berada pada titik koordinat 5'50'20”-5 50'25'LS dan 106 38'30"$106^{\circ} 38^{\prime} 20^{\prime \prime B T}$. Pulau Pari memiliki luas wilayah \pm 41.32 ha dan memiliki topografi tanah yang datar dengan

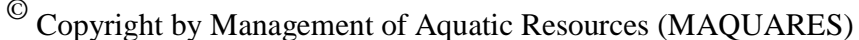


ketinggian \pm 0-3 mdpl. Tipe pantai di Pulau Pari berpasir putih dan bervegetasi mangrove (hanya di bagian Utara dan Barat).

Parameter lingkungan perairan

Hasil yang didapat dari parameter lingkungan perairan disajikan dalam Tabel 1 di bawah ini :

Tabel 1. Nilai Parameter Kualitas Perairan di Pulau Pari, Kepulauan Seribu

\begin{tabular}{clcccc} 
No & Parameter Lingkungan & Satuan & Stasiun I & Stasiun II & Stasiun III \\
\hline 1 & Suhu udara & ${ }^{\circ} \mathrm{C}$ & 29 & 30 & 29 \\
2 & Suhu air & ${ }^{\circ} \mathrm{C}$ & 32.2 & 34.5 & 32.2 \\
3 & Kedalaman & $\mathrm{cm}$ & 60 & 30 & 30 \\
4 & Kecerahan & $\mathrm{cm}$ & $\sim$ & $\sim$ & $\sim$ \\
5 & Kecepatan arus & $\mathrm{m} / \mathrm{s}$ & 0,06 & 32 & 0,06 \\
6 & Salinitas & $\% o$ & 32 & 4,0 & 33 \\
7 & DO & $\mathrm{mg} / 1$ & 4,30 & 8,81 & 8,06 \\
8 & pH & - & 8,51 & 0,06 & 0,04 \\
9 & Nitrat & $\mathrm{mg} / 1$ & 0,04 & & \\
\hline
\end{tabular}

Analisis kandungan nitrat pada polip karang

Hasil dari pengukuran nitrat pada beberapa jenis karang disajikan dalam Tabel 2 di bawah ini :

Tabel 2. Konsentrasi Nitrat pada Beberapa Jenis Karang pada Stasiun I,II dan III di Pulau Pari, Kepulauan Seribu

\begin{tabular}{llccc}
\multirow{2}{*}{ No } & \multirow{2}{*}{ Jenis Karang } & \multicolumn{3}{c}{ Konsentrasi Nitrat (mg/l) } \\
\cline { 3 - 5 } & & Stasiun I & Stasiun II & Stasiun III \\
\hline 1 & Acropora palifera & 0,7 & 0,7 & 1 \\
2 & Acropora divaricata & 1,5 & 0,9 & 0,7 \\
3 & Porites cylindrica & 1,1 & 0,5 & 0,5 \\
\hline
\end{tabular}

\section{Persentase penutupan karang}

Hasil yang didapat dari pengamatan penutupan karang dengan metode line transek disajikan dalam Tabel 3 di bawah ini :

Tabel 3. Persentase Penutupan Karang pada Stasiun I, II dan III di Pulau Pari, Kepulauan Seribu dengan Metode Line Transek

\begin{tabular}{llccccccc}
\hline \multirow{2}{*}{ No } & \multirow{2}{*}{ Jenis Penutupan } & \multicolumn{9}{c}{ Stasiun } \\
\cline { 3 - 8 } & & \multicolumn{2}{c}{ I } & \multicolumn{2}{c}{ II } & \multicolumn{2}{c}{ III } \\
\cline { 3 - 8 } & & $\mathbf{c m}$ & \% & $\mathbf{c m}$ & \% & cm & \% \\
\hline \multirow{2}{*}{1} & Karang hidup & 910 & 36,4 & 560 & 22,4 & 1680 & 67,2 \\
2 & Karang mati & 420 & 16,8 & 110 & 4,4 & 100 & 4 \\
3 & Pecahan karang & 805 & 32,2 & 1200 & 48 & 450 & 18 \\
4 & Pasir & 365 & 14,6 & 630 & 25,2 & 270 & 10,8 \\
\hline & Jumlah & 2500 & 100 & 2500 & 100 & 2500 & 100 \\
\hline
\end{tabular}




\section{Hubungan nitrat dengan densitas zooxanthellae}

Diperoleh hubungan konsentrasi nitrat dengan densitas zooxanthellae pada beberapa jenis karang dapat dilihat dalam Gambar 2,3 dan 4 berikut ini :

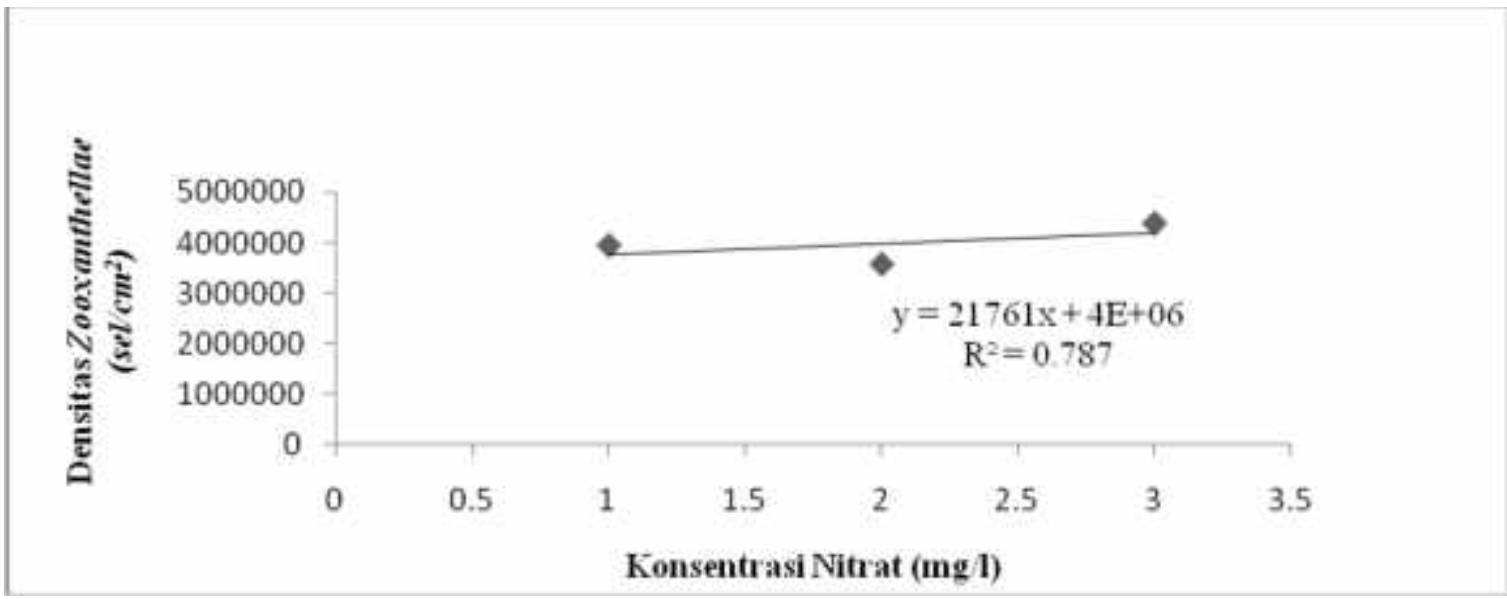

Gambar 2. Grafik Hubungan Nitrat dengan Densitas Zooxanthellaepada Karang Acropora palifera

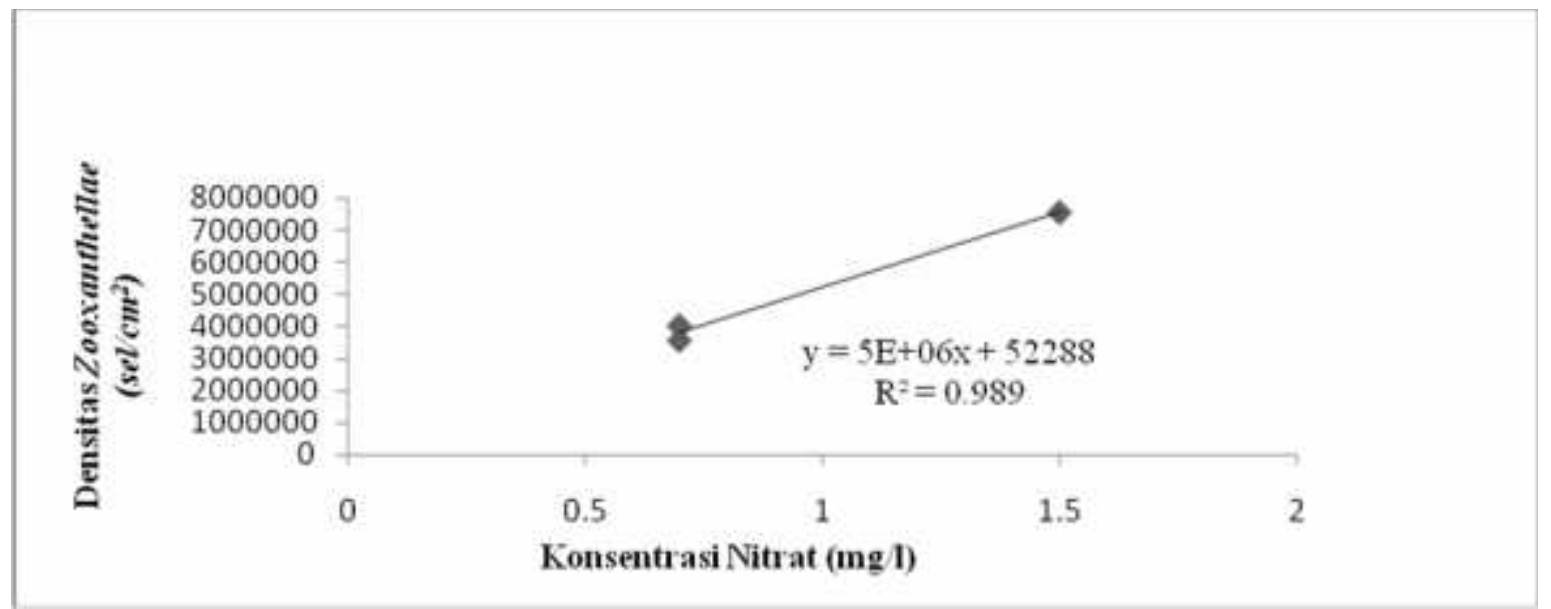

Gambar 3. Grafik Hubungan Nitrat dengan Densitas Zooxanthellaepada Karang Acropora divaricata

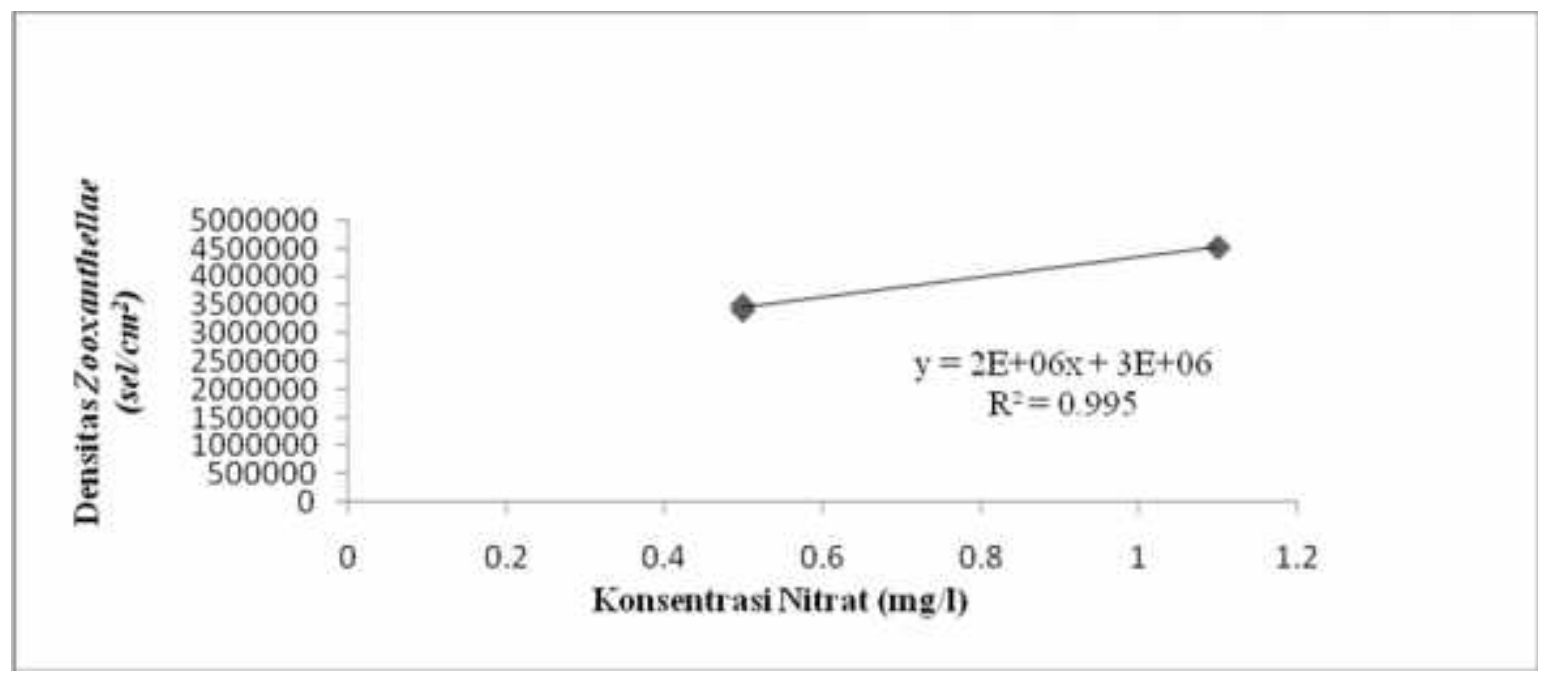

Gambar 4. Grafik Hubungan Nitrat dengan Densitas Zooxanthellaepada Karang Porites cylindrical

Berdasarkan Gambar 6,7 dan 8 grafik regresi linier sederhana yang didapat menunjukkan arah hubungan antara variabel bebas X (nitrat) dengan variabel terikat Y (densitas zooxanthellae) adal searah atau positif bisa

${ }^{(C)}$ Copyright by Management of Aquatic Resources (MAQUARES) 
dilihat dari arah garis yang menuju ke atas. Dalam hal ini kenaikan variabel bebas X diikuti dengan kenaikan variabel terikan $\mathrm{Y}$ dan begitu juga sebaliknya. Tampak juga titik-titik menyebar dengan pola linier tidak terlalu berjauhan.

Pengukuran parameter lingkungan perairan dilakukan pada saat penelitian di lapangan untuk mengetahui kualitas kondisi perairan di masing-masing stasiun. Hasil dari pengukuran suhu air pada lokasi penelitian di Pulau Pari menunjukkan kisaran suhu perairan $32-34{ }^{\circ} \mathrm{C}$, suhu tersebut masih dalam kategori baik untuk kehidupan dan perkembangbiakan terumbu karang juga masih sesuai dengan suhu yang dijumpai pada permukaan laut yang normal. Menurut Supriharyono (2007), pertumbuhan karang optimal pada kisaran temperatur $25-32^{\circ} \mathrm{C}$. Hasil pengukuran salinitas pada lokasi penelitian di Pulau Pari antara 32-33 \%o, hal ini menunjukkan salinitas di lokasi penelitian masih termasuk dalam kategori baik bagi pertumbuhan terumbu karang juga biota yang hidup di sekitar terumbu karang, Guntur (2011) menyatakan terumbu karang dapat bertahan hidup pada salinitas laut normal yaitu salinitas 32-35\%o, dengan batas toleransi berkisar antara 27-42\%o.

Kecepatan arus yang diperoleh pada lokasi penelitian di Pulau Pari $0.06-0.13 \mathrm{~m} / \mathrm{s}$, hal ini menunjukkan bahwa arus pada saat penelitian cukup cepat dikarenakan angin yang bertiup cukup kencang. Pergerakan air (arus) diperlukan untuk tersedianya aliran yang membawa nutrien dan bahan bahan organik yang di perlukan oleh karang dan zooxanthellae makanan dan oksigen serta menghindarkan karang dari pengaruh sedimentasi menutupi pemukaan karang sehingga berakibat pada kematian karang (Haapkyla et al., 2009).

Kecerahan air pada lokasi penelitian di Pulau Pari tidak terhingga karena ketinggian air tidak terlalu dalam kurang dari 1 meter sehingga masih jernih dan bisa dilihat secara visual kondisi di bawah air. Kecerahan perairan adalah suatu kondisi yang menunjukkan kemampuan cahaya untuk menembus lapisan air pada kedalaman tertentu. Pada perairan alami kecerahan sangat penting karena erat kaitannya dengan aktifitas fotosintesa (Guntur, 2011).

Kedalaman air pada lokasi penelitian di Pulau Pari berkisar $30-60 \mathrm{~cm}$, tidak terlalu dalam dan masih dapat ditembus oleh cahaya matahari. Kemampuan intensitas cahaya matahari dipengaruhi oleh kedalaman agar terumbu karang dapat berkembang dengan baik. Menurut Supriharyono (2007), terumbu karang tumbuh pada kedalaman kurang dari $25 \mathrm{~m}$ dan tidak dapat hidup di perairan yang lebih dalam dari $50-70 \mathrm{~m}$. Alasan adanya pembatasan kedalaman adalah kebutuhan karang hermatipik terhadap cahaya.

$\mathrm{pH}$ adalah derajat keasaman yang menyatakan tingkat keasaman atau kebasaan suatu larutan dalam hal ini perairan laut. Derajat keasaman pada lokasi penelitian di Pulau Pari sekitar 8,5-8,8 yang menunjukkan pH air laut adalah basa. Menurut Dahuri et al. (2001), derajat keasaman (pH) di suatu perairan yang normal berkisar 8,0-8,3.

Kadar oksigen terlarut pada lokasi penelitian di Pulau Pari berkisar 4,4-5,06 mg/l. Kadar tersebut masih sesuai dengan kadar normal oksigen terlarut pada lapisan permukaan laut. Kondisi suatu badan air dapat dikatakan baik jika nilai konsentrasi oksigen terlarutnya besar. Menurut Sukarno (1995), kadar oksigen di permukaan laut yang normal berkisar antara 4,0-6,0 mg/l.

Secara umum kandungan nitrat di Perairan pulau Pari masih sesuai dengan kandungan nitrat yang umum dijumpai di perairan laut. Kandungan nitrat yang normal di perairan laut umumnya berkisar antara 0,01 - 50 mg/I. Menurut Effendi (2003), kadar Nitrat yang masih tergolong baik untuk kesehatan karang berdasarkan hasil penelitian adalah $0,040 \mathrm{mg} / \mathrm{l}$.

Berdasarkan hasil pengamatan yang dilakukan pada saat penelitian di lapangan pada reef flat Pulau Pari ditemukan 3 jenis karang yaitu Acropora sp., Porites sp., dan Montipora sp. Perhitungan nilai persentase penutupan karang hidup di lokasi sampling Pulau Pari, Kepulauan Seribu, Jakarta stasiun I (dermaga) sebesar $36.4 \%$, stasiun II (pemukiman penduduk) sebesar 22,4\% dan stasiun III (jauh dari pemukiman dan aktivitas penduduk) sebesar 67,2\%. Dapat diketahui penutupan karang hidup di daerah reef flat Pulau Pari sekitar 22,4 67,2\%. Menurut KEPMEN LH No. 4 Tahun 2001, untuk terumbu karang di daerah penelitian di pulau Pari Kepulauan Seribu berada pada kategori buruk, sedang dan baik yang dilihat pada persentase karang hidup.

Data hasil kelimpahan zooxanthellae dari beberapa jenis karang Acroporapalifera, Acropora divaricata dan Poritescylindrica menunjukkan bahwa kelimpahan zooxanthellae paling tinggi pada stasiun I (dermaga), kemudian stasiun III (jauh dari pemukiman dan aktivitas penduduk) setelah itu stasiun II (pemukiman penduduk). Hal yang menyebabkan perbedaan kelimpahan zooxanthellae pada setiap stasiun diperkirakan oleh adanya perbedaan tingkat pemanfaatan di lingkungan sekitar. Menurut Cook et al., (1988), menyatakan bahwa pola kelimpahan zooxanthellae bervariasi tergantung pada hewan inangnya, lokasi dan faktor lingkungan dan Purnomo (2014) menyatakan bahwa kepadatan Zooxanthellae di alam berfluktuasi karena efek faktor lingkungan.

Data kelimpahan zooxanthellae pada kawasan reef flat stasiun I jenis karang Acropra palifera 3.948.252 $\mathrm{sel} / \mathrm{cm}^{2}$, Acropora divaricata $7.549 .432 \mathrm{sel} / \mathrm{cm}^{2}$ dan Porites cylindrical $4.529 .190 \mathrm{sel} / \mathrm{cm}^{2}$. Faktor yang menyebabkan kelimpahan zooxanthellae di daerah dermaga tinggi karena banyaknya masukan nutrien dari daerah perairan sekitar dan dari daratan yang mengalir ke reef flat dengan karang hidup yang masih cukup banyak. Menurut Reid et al., (2011), arus permukaan akan mendistribusikan sebagian besar nutrien yang masuk dari daerah pesisir juga karena pasang surut sehingga menambah pasokan bahan organik bahan anorganik yang diperlukan oleh tumbuhan laut. Sementara nitrogen dan fosfor berasal dari penguraian bahan organik oleh bakteri yang merupakan bagian penting dari siklus nutrien. Nutrien yang berada di perairan memberikan nutrisi untuk kelangsungan hidup bagi zooxanthellae. 
Kelimpahan zooxanthellae pada reefflat stasiun II (pemukiman penduduk) pada jenis karang Acropra palifera $3.574 .941 \mathrm{sel} / \mathrm{cm}^{2}$, Acropora divaricata $4.125 .333 \mathrm{sel} / \mathrm{cm}^{2}$ dan Porites cylindrical $3.421 .911 \mathrm{sel} / \mathrm{cm}^{2}$. Hasil dari pengamatan kelimpahan zooxanthellae pada stasiun II lebih rendah dibandingkan dengan stasiun I (dermaga). Letak stasiun II yang berada di sekitar pemukiman penduduk dikhawatirkan mempengaruhi pertumbuhan dan kehidupan karang, sehingga menyebabkan kelimpahan zooxanthellae menurun. Kondisi perairan di stasiun II cukup meprihatinkan banyak penduduk sekitar yang membuang sampah di sekitar perairan tersebut, limbah rumah tangga dari penduduk kemungkinan juga mengalir di sekitar perairan reef flat stasiun II.

Faktor yang dimungkinkan mempengaruhi kelimpahan zooxanthellae di stasiun II rendah adalah sedimentasi yang cukup tinggi dan pencemaran lingkungan perairan. Sedimentasi dapat terjadi karena lalu lalang kapal yang melintas di sekitar stasiun II dan menyebabkan pengaruh langsung dengan adanya pergerakan arus yang cukup kencang, sehingga substrat pasir terangkat dan menutupi polip pada karang yang masih hidup. Sedangkan, pengaruh tidak langsung dari sedimen yang terangkat akan mengapung di permukaan perairan dan menghalangi masuknya intensitas cahaya yang akan digunakan zooxanthellae untuk fotosintesis. Menurut Kordi (2010), sedimen baik di dalam air maupun di atas karang mempunyai pengaruh negatif tehadap karang. Kebanyakan karang hermatifik tidak dapat bertahan dengan adanya sedimen yang berat, yang menutupi dan menyumbat stuktur pemberian makanan.

Kelimpahan zooxanthellae pada stasiun III (jauh dari pemukiman dan aktivitas penduduk) pada jenis karang Acropra palifera $4.383 .476 \mathrm{sel} / \mathrm{cm}^{2}$, Acropora divaricata $4.028 .944 \mathrm{sel} / \mathrm{cm}^{2}$ dan Porites cylindrical 3.502 .817 $\mathrm{sel} / \mathrm{cm}^{2}$. Hasil tersebut lebih tinggi dibandingkan dengan stasiun II (pemukiman penduduk), hal ini dikarenakan kondisi terumbu karang di stasiun III baik bisa dilihat dari data persentase penutupan karang hidup 67,2 \%. Stasiun III ini merupakan Area Perlindungan Laut (APL) yang dikelola oleh Pusat Penelitian Oseanografi (P2O) LIPI yang kelestarian pada area terumbu karangnya rutin dilakukan monitoring, sehingga kondisi ekosistem terumbu karang di stasiun III masih termasuk kategori baik. Menurut Moberg and Folke (1997), mengemukakan bahwa status nutrisi bagi kebutuhan zooxanthellae dapat dijadikan sebagai indikator kesuburan terumbu karang. Lingkungan eksternal di kawasan perairan terumbu karang, pada setiap waktu densitas zooxanthellae berfluktuasi, tergantung pada kualitas lingkungan perairan.

Nutrien yang dihasilkan oleh polip karang berupa nitrogen, salah satu unsur dari nitrogen adalah nitrat. Nitrat yang dihasilkan karang dari hasil metabolisme polip karang dapat langsung dimanfaatkan oleh zooxanthellae, melalui dekomposisi bahan organik yang dibantu oleh beberapa jenis bakteri di dalam karang, Saputri et al., (2016) menyatakan bahwa 3 genera bakteri yang teridentifikasi yaitu Listeria sp.Bacillus sp., Bacillus sp., dan Micrococcus sp., bakteri tersebut merupakan bakteri anaerob fakultatif yang mampu hidup dalam keadaan tidak terdapat oksigen dan bakteri tersebut memiliki peranan penting dalam menguraikan bahan organik di perairan. Kandungan nitrat yang ada di dalam polip karang dapat berpengaruh pada densitas zooxanthellae yang berlindung di polip karang.

Data analisa yang diperoleh menunjukkan besarnya persentase pengaruh variable bebas (total nitrat) terhadap variable terikatnya (densitas zooxanthellae). Nilai koefisien determinasi $\mathrm{R}^{2}$ antara nitrat dengan densitas zooxanthellae pada masing-masing jenis karang yang dominan memiliki nilai yang berbeda yaitu karang Acropora palifera diperoleh $\mathrm{R}^{2}=0.787$ dapat diartikan bahwa variabel bebas $\mathrm{X}$ memiliki pengaruh kontribusi sebesar 78,7 $\%$ terhadap variabel Y 21,3\%, pada jenis karang Acropora divaricata diperoleh $\mathrm{R}^{2}=0.989$ memiliki pengaruh kontribusi sebesar 98,9 \% terhadap variabel Y 1,1\% dan jenis karang Porites cylindrica $\mathrm{R}^{2}=0.955$ memiliki pengaruh kontribusi sebesar 95,5\% terhadap variabel Y 4,5\% lainnya dipegaruhi faktor lain diluar variabel X dari hasil tersebut menunjukkan bahwa nilai $\mathrm{R}^{2}$ diatas 0,5 yang berarti semakin erat hubungan antara variabel $\mathrm{X}$ dan $\mathrm{Y}$. Semakin tinggi kandungan nitrat di dalam polip karang, maka semakin tinggi pula densitas zooxanthellae yang dikandungnya.

Berdasarkan hasil regresi antara hubungan nitrat dan densitas zooxanthellae menunjukkan $\mathrm{R}^{2}$ memiliki nilai diatas 0,5 yang memiliki arti adanya hubungan keeratan yang baik antara variabel $\mathrm{X}$ (konsentrasi nitrat) dengan variabel Y (densitas zooxanthellae).

Hubungan nitrat dengan nilai densitas zooxanthellae menunjukkan bahwa hubungan yang didapat adalah semakin tingginya kandungan nitrat pada karang tersebut maka makin tinggi pula densitas zooxanthellae pada suatu karang. Menurut Purnomo (2014) menyatakan bahwa kandungan nitrat yang tinggi di dalam polip karang dapat meningkatkan densitas zooxantellae, selanjutnya dikemukakan bahwa peningkatan zooxanthellae diikuti oleh penempatan zooxanthellae dalam polip sehingga karang dapat tumbuh dengan baik.

\section{KESIMPULAN}

Kesimpulan yang dapar diambil dari penelitian adalah sebagai berikut:

1. Kandungan nitrat polip karang pada daerah reef flat Pulau pari di stasiun I pada karang jenis Acropora palifera $0,7 \mathrm{mg} / \mathrm{l}$, Acropora divaricata $1,5 \mathrm{mg} / \mathrm{l}$ dan Porites cylindrical $1,1 \mathrm{mg} / \mathrm{l}$, stasiun II Acropora palifera 0,7 mg/l, Acropora divaricata $0,9 \mathrm{mg} / \mathrm{l}$ dan Porites cylindrical 0,5 mg/l, stasiun III Acropora palifera $1 \mathrm{mg} / \mathrm{l}$, Acropora divaricata $0,7 \mathrm{mg} / \mathrm{l}$ dan Porites cylindrical $0,5 \mathrm{mg} / \mathrm{l}$; 
2. Densitas zooxanthellae pada polip karang daerah reef flat Pulau Pari di stasiun I pada jenis karang Acropra palifera $3.948 .252 \mathrm{sel} / \mathrm{cm}^{2}$, Acropora divaricata $7.549 .432 \mathrm{sel} / \mathrm{cm}^{2}$ dan Porites cylindrical $4.529 .190 \mathrm{sel} / \mathrm{cm}^{2}$, stasiun II Acropra palifera $3.574 .941 \mathrm{sel} / \mathrm{cm}^{2}$, Acropora divaricata $4.125 .333 \mathrm{sel} / \mathrm{cm}^{2}$ dan Porites cylindrical $3.421 .911 \mathrm{sel} / \mathrm{cm}^{2}$, stasiun III Acropra palifera $4.383 .476 \mathrm{sel} / \mathrm{cm}^{2}$, Acropora divaricata $4.028 .944 \mathrm{sel} / \mathrm{cm}^{2}$ dan Porites cylindrical $3.502 .817 \mathrm{sel} / \mathrm{cm}^{2}$;

3. Nilai koefisien determinasi $\mathrm{R}^{2}$ antara nitrat dengan densitas zooxanthellae pada masing-masing jenis karang yang dominan memiliki nilai yang berbeda yaitu karang Acropora palifera diperoleh $\mathrm{R}^{2}=0.787$ dapat diartikan bahwa variabel bebas X memiliki pengaruh kontribusi sebesar 78,7 \% terhadap variabel Y 21,3\%, pada jenis karang Acropora divaricata diperoleh $\mathrm{R}^{2}=0.989$ memiliki pengaruh kontribusi sebesar 98,9\% terhadap variabel Y $1,1 \%$ dan jenis karang Porites cylindrica $\mathrm{R}^{2}=0.955$ memiliki pengaruh kontribusi sebesar 95,5\% terhadap variabel Y 4,5\% lainnya dipegaruhi faktor lain diluar variabel $\mathrm{X}$ dari hasil tersebut menunjukkan bahwa nilai $\mathrm{R}^{2}$ diatas 0,5 yang berarti semakin erat hubungan antara variabel $\mathrm{X}$ dan $\mathrm{Y}$. Semakin tinggi kandungan nitrat di dalam polip karang, maka semakin tinggi pula densitas zooxanthellae yang dikandungnya.

\section{UCAPAN TERIMA KASIH}

Penulis mengucapkan terima kasih kepada Dr.Ir. Haeruddin, M.Si., Dr.Ir. Bambang Sulardiono, M.Si., dan Dr.Ir. Suryanti, M.Pi yang telah memberikan kritik dan saran untuk perbaikan penelitian ini.

\section{DAFTAR PUSTAKA}

Candrasari, K., Azis Rifai dan Gentur Handoyo. 2015. Peramalan Nilai MSL Berdasarkan Data Pasang Surut dengan Metode Admiralty dan Autoregressive Integrated Moving Average (Arima) di Perairan Pulau Pari Kepulauan Seribu. Jurnal Oseanografi, 4(1):28 - 34.

Cook, C.B, 1988. Eleven Temperatures And Bleanching On A High Latitude Coral Reef : The 1988 Bermuda Event Coral Reefs, 9: 45-9.

Dahuri, R., Jacob Rais, Sapta Putra Ginting dan M. J. Sitepu, 2001. Pengelolaan Sumber Daya Wilayah Pesisir dan Lautan Secara Terpadu. Pradnya Paramita, Jakarta.

Effendi, H. 2003. Telaah Kualitas Air bagi Pengelolaan Sumberdaya dan Lingkungan Perairan. Kanisius, Yogyakarta.

English, S., Wilkinson, C and Baker, V. 1997. Survey Manual for Tropical Marine Resources. Australian Institute of Marine Science. Queensland, Australia. 390pp.

Guntur. 2011. Ekologi Karang pada Terumbu Karang Buatan. Ghalia Indonesia, Bogor.

Haapkyla, J.,.Seymour, A.S. Trebilko, 2009. Coral Disease Prevelence and Healt in the Wakatobi Marine Park, Sout-east Sulawesi, Indonesia, Marine Biologi U.K., 87:403-414.

Hartono. 2008. SPSS 16.0 Analisa Data Statistik dan Penelitian. Cetakan I. Pustaka Pelajar. Yogyakarta.

Hutagalung, H. P. dan A. Rozak. 1997. Metode Analisis Air Laut, Sedimen dan Biota. Buku 2. LIPI. Jakarta.

Kordi, M.G.H.K. 2010. Ekosistem terumbu karang. Rineka Cipta. Jakarta. Hlm.:81-83.

Marubini, F. and Davies, P.S. 1996. Nitrate Increase Zooxantellae Population Density and reduces Skeletogenesis in Corals, Marine Biology, 127:319-328.

Morberg, F. and Folke, C. 1999. Ecological Goods and Services of Coral Reef Ecosystems. Ecological Economics, 29:215-233.

NOAA. 2009. http://oceanoxplorer.noaa.gov/Terumbu Karang Melindungi Harta Karun Alam.. 6 Juni 2016.

Notoatmodjo, S. 2002. Metodologi Penelitian Kesehatan. Rineka Cipta, Jakarta, 208 hlm.

Nordemar, J., M. Nystrom, R. Dizon. 2003. Effect of elevated seawater temperature and nitrat enrichment on the branching coral Porites cylindrica in the absence of particular food. Mar. Biol. 142 : 669-672.

Purnomo, P.W. 2011. Keragaman Genetik Zooxanthellae dari Beberapa Sumber Inang di Perairan Terumbu Karang Pulau Bokor Jepara. Jurnal Saintek Perikanan, 7(1):39-45.

2014. TranslocationStudy of Some Zooxanthellae Clade to the Survival and Growth of Goniastrea aspera After Bleaching. International Journal of Marine and Aquatic Resource Concervation and Coexsistence Research Article, 1(1):50-54.

Reid, C,, J. Marshall, D. Logan and D. Kleine. 2011. Terumbu Karang dan Perubahan Iklim. CoralWatch, The University of Queensland, hlm 63.

Saputri, R. A., N. Widyorini, P. W. Purnomo. 2016. Identifikasi dan Kelimpahan Bakteri Pada Jenis Karang Acropora sp. di Reef Flat Terumbu Karang Pulau Panjang Jepara. Skripsi Jurusan Perikanan, Universitas Diponegoro.

Sukarno. 1995. Mengenal Ekosistem Terumbu Karang Berbasis Masyarakat dengan Metode Manta Tow, proyekCRMP. Jakarta Indonesia.

Supriharyono. 2007. Pengelolaan Konservasi Ekosistem Terumbu Karang. Djambatan, Jakarta. 